\title{
PSYCHE.
}

\section{NOTES ON MELITTIA CUCURBITAE AND A RELATED SPECIES.}

BY SAMUEL HUBBARD SCUDDER, CAMBRIDGE, MASS.

The tolerably full account of Melittia cucurbitae recently given by Mr. J. A. Lintner in his second Report on the injurious insects of New York recalled to me some observations made on the ravages of this insect in the squash vines on Cape Cod, and from my notes made at the time, now more than twenty-five years ago, I condense the following statement.

My examination was made in the early part of September, and there were to be found at that time two kinds of aegerian larvae within the plants, a larger and a smaller, and in the ground were found cocoons containing larvae of the larger kind-which subsequent observation showed remained through the winter without changing to chrysalis, and also a number of pupal exuviae protruding from the surface of ground which had not been hoed for a month or more.

There are thus apparently two species of aegerians destructive to the squash, and it seems to be probable that the one represented by the smaller larvae and the chrysalis-skins is either a later appearing species or that it is doublebrooded, the brood represented by the smaller larvae in September being the later. There can be little doubt that both were aegerians, as they agreed closely in all structural peculiarities, and they could hardly have been differ- erent stages of the same species, since they differed so much in the color of the head and thoracic segments and in the general markings. The following description of the larva of $M$. cucurbitae, fuller than before published, is drawn up from my notes.

Head very dark brown, deepening into black, with a median white band reaching to the frontal triangle and passing down its sides; a few scattered hairs are seen. Body white, the dorsal vessel visible through the cuticle, the surface smooth, but with two or three hairs on each segment, and on the terminal segment some faint light brown spots and four backward-projecting hairs. The first thoracic segment has on the dorsal surface two oblique, curved. light brown bands, nearly meeting posteriorly, their concavities outward; between their extremities on the front of the segment are a pair of transverse, almost microscopic, semicircular lines opening forwards. On second and third thoracic segments (my notes fail to say whether above or below) a transverse row of hair-bearing, scarcely perceptible, tubercles. Legs light brown; in place of prolegs, rings of black bristles. Spiracles light horn-color, surrounded by white, and this by a horny areola. Length $25 \mathrm{~mm}$; breadth a little more than $6 \mathrm{~mm}$.

As this and the smaller larva were at first taken for different stages of the same species, the difference in their habits was not so carefully noted as it should have been. The present species was, however, by far the more destruc- 
tive, being ten times more numerous than the other; nearly forty were taken from the inside of a single plant, they being found concealed in all parts from below the ground as far as they could burrow, to the base of the leaf stalks, and some were even in the squash itself; besides these, in the hill in which the same plant was growing, over twenty larvae were found in their chrysalis cases. They cast most of their excrement through holes eaten to the surface of the stalks. They appear to commence their work near the surface of the ground, and to work their way in each direction.

When ready for their change, they eat their way out of the stalk, reach the ground (probably by a thread, for they can spin one) enter the ground and make their cocoon there ; this is formed externally of grains of earth adhering to silk, and is of considerable stoutness though very thin; it is of a light brown color within and blackish without, so that when the earth is removed, the cocoon has a reticulated appearance, from the brown showing through the black; the innermost layer of all is white. Some of these cocoons were kept, and the larvae were living within them on the 26th of the following May, having remained unchanged in the larval condition throughout the winter. They subsequently died. Thirty or forty cocoons were opened in the hills only to find the larva within.

This is all the history of this species which was followed. The second species has very nearly the same habits, excepting that it perforates the base of the leaf stalks themselves and lives in the leaf stalks, often curled up. $M$. cucurbitae was also found there but not so frequently, and the present species seemed to prefer in addition the harder parts of the plant, such as the junction of the leaf and stalk, of the leaf stalk and main stalk, etc. The following is a description of the smaller species.

Head jet-black. Body white, with a faint, dusky stigmatal band. Upper surface of first thoracic segment nearly black; a transverse series of eight brown spots on each segment behind the first, two faint ones being dorsal, one on each side infra-stigmatal, and the others pleural; those of the thoracic rings are much the most conspicuous, and on the abdominal rings there is a brown dot on each ring in front of and a little within the dorsal spots; the last segment is brown above with spots similar to those of $M$. cucurbitae but more distinct; hairs as in that species. Length $13 \mathrm{~mm}$.; breadth $2.5 \mathrm{~mm}$.

No difference was noted between the cocoons beneath the surface with living larvae (M. cucurbitae) and those of the present species which were emptied, the chrysalis forcing off (how?) the entire end of the cocoon, and by means of the hooks on the abdominal rings working its way to the surface. A single larva, kept in captivity, made a cocoon in a small box partly filled with earth, and it was noted that the cocoon was thinner than that of $M$. cucurbitae.

Brief additional notes on $M$. cucurbitae will be found in Papilio, v. 2, p. 50 , by N. Coleman ; and in Bull. Brooklyn entom. soc., v. 6, p. ro, by G. D. Hulst. 

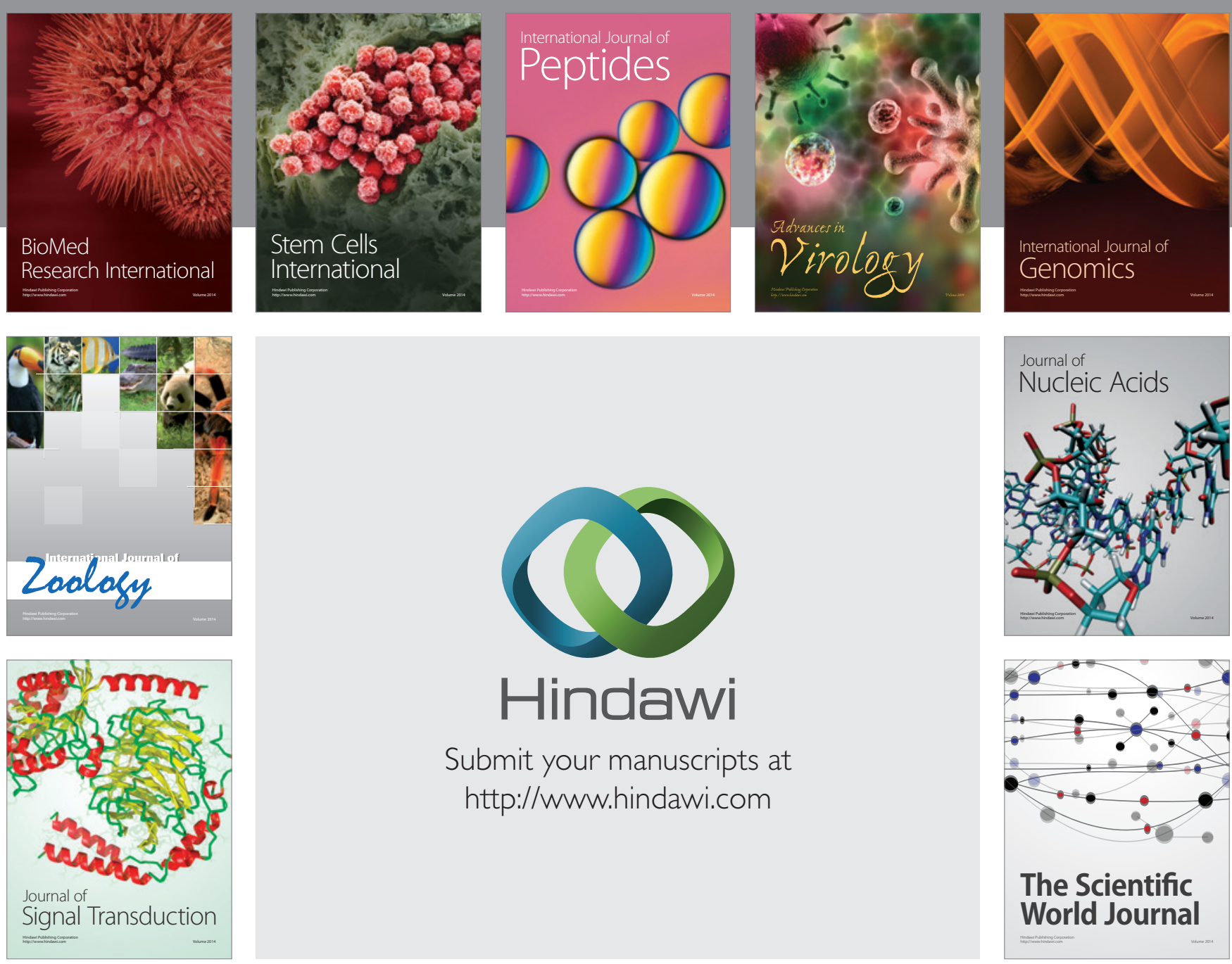

Submit your manuscripts at

http://www.hindawi.com
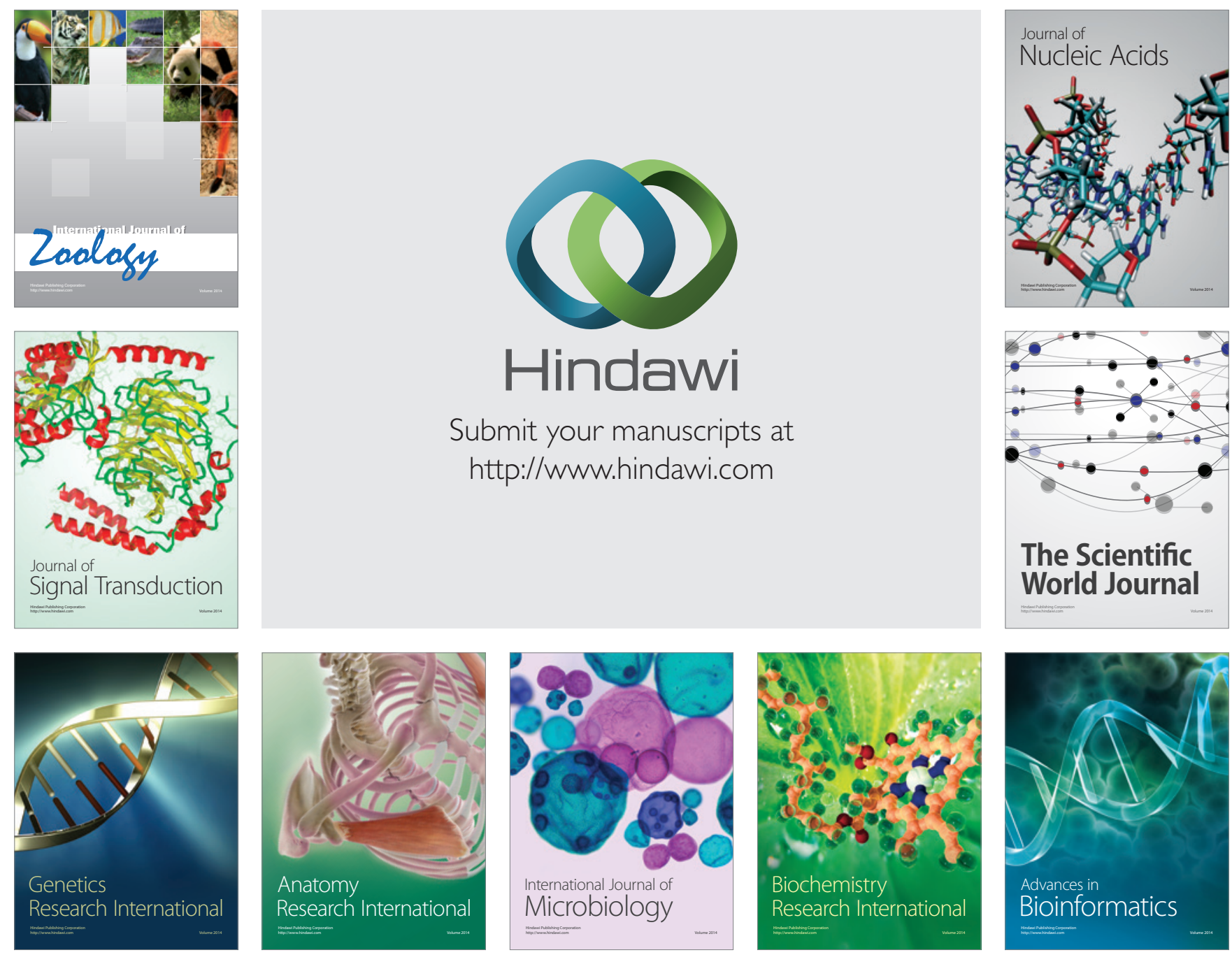

The Scientific World Journal
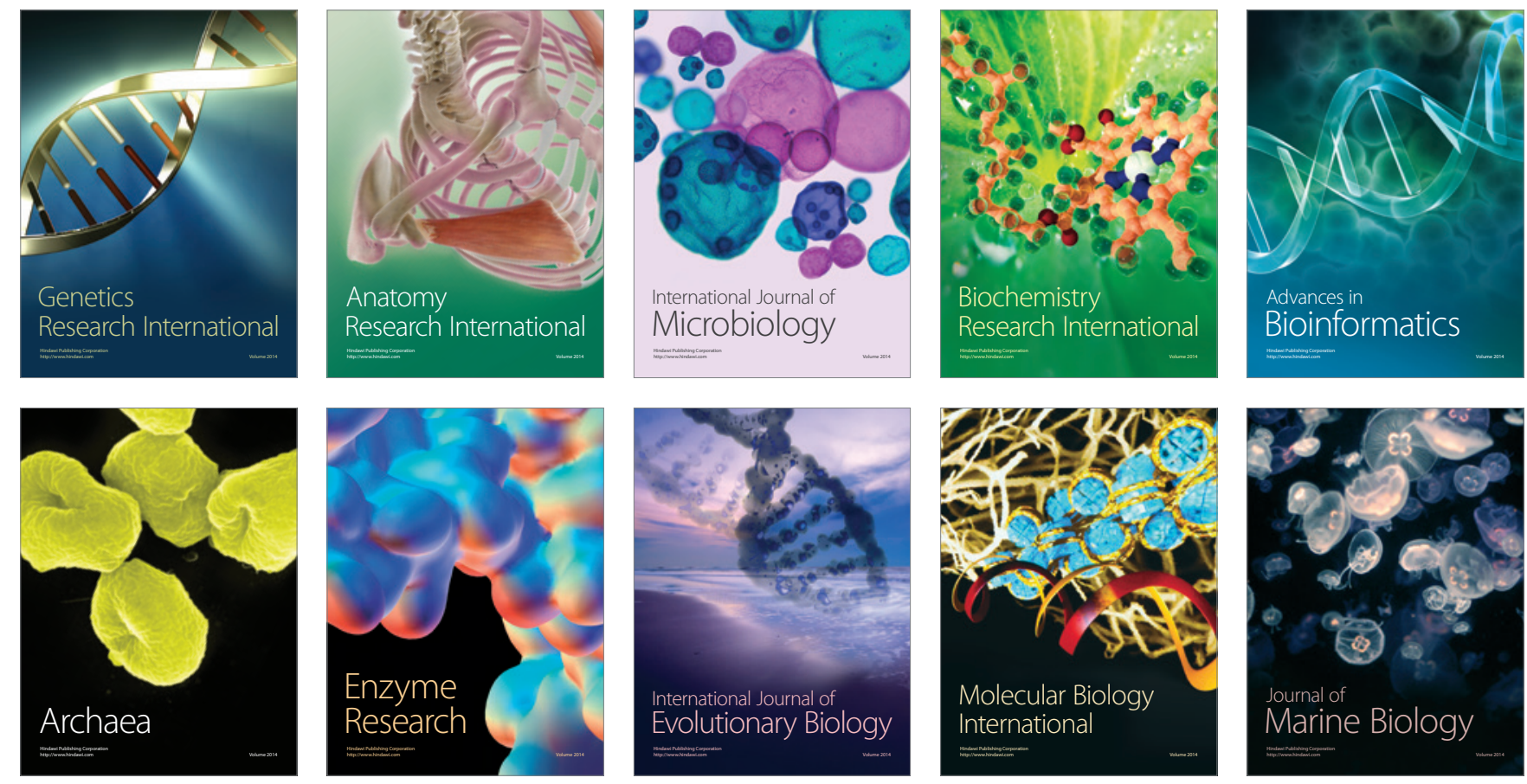